\title{
A rare cause of recurrent peripheral facial palsy
}

\author{
Uma causa rara de paralisia facial periférica recorrente \\ João Pinho, Sofia Rocha, Álvaro Machado, Esmeralda Lourenço
}

Recurrent peripheral facial palsy (PFP) is not uncommon and it is reported in 3 to $15 \%$ of idiopathic PFPs. Other etiologies include intracranial compressive tumors, parotid gland tumors or inflammation, recurrent otitis media, head trauma, multiple sclerosis, sarcoidosis, tuberculosis, Lyme disease, HIV, and the rare Melkersson-Rosenthal Syndrome (MRS). The MRS is a non-necrotizing granulomatous disease characterized by PFP, lingua plicata and orofacial edema, even though the classic triad is reported in only from 20 to $30 \%$ of the patients ${ }^{1}$. We describe a patient with recurrent alternating PFP with MRS.

\section{CASE REPORT}

A 31 year-old man presented with a three-day history of left sided retro-auricular dull pain, progressive face asymmetry with sensation of foreign body in the left eye, liquid loss through the left corner of his mouth while drinking, and a change in taste. He remembered having had a similar episode six years earlier. He had been followed-up by dermatologists because of a persistent lip swelling, which developed insidiously during his early 20s. He had been treated with oral metronidazol and topical agents for suspicion of fungal infection, he was submitted to a lip biopsy that was reported as unspecific, and had discontinued his treatment. During both episodes of facial palsy, there was a transient increase in lip swelling. He was otherwise healthy. Family history of facial palsy was negative. Examination revealed an isolated left PFP, edema, scaling and fissuring of the upper lip, and lingua plica$t a$ with deep central tongue fissure, radiating fissures and irregular tongue edges (Figure). The patient was treated with a seven-day tapering scheme of oral prednisolone, motor rehabilitation. Within two weeks, he had recovered fully with partial improvement of lip swelling. Four weeks later the patient presented with a right PFP and increased upper lip edema, and no signs of previous left PFP. He was treated again with oral prednisolone and motor rehabilitation, recovering completely after four weeks. Blood testing was normal, including infectious and immunological screen. Thoracic X-ray was also normal. The brain magnetic resonance image (MRI) was normal. He has been asymptomatic for three years.

\section{DISCUSSION}

The MRS etiology is unknown but autoimmune, allergic, infectious and genetic factors are proposed. Perivascular lymphocytic inflammatory infiltrates and non-caseating epitheloid granulomas are the main findings in lip biopsies ${ }^{2}$. Finding of decreased $\mathrm{C} 1$ inhibitor function and contact sensitivity to food additives supports the immunological hypothesis ${ }^{3}$. Familial occurrence of MRS and identification of a de novo $\mathrm{t}(9 ; 21)(\mathrm{p} 11 ; \mathrm{p} 11)$ translocation in one patient suggest a role for genetic factors ${ }^{4}$. The MRS should be suspected in patients with PFP and typical cutaneous, lip and tongue findings. Recognition of the classic triad prevents submitting the patient to unnecessary workup. Lip biopsy is required for definite diagnosis, but typical histological findings may be absent ${ }^{4}$. Treatment with topic, oral and intravenous steroids, salazosulfapyridine, methotrexate, thalidomide and irradiation has been reported, but results are frequently disappointing and progressive disability may be developed ${ }^{5}$.

The rare cause of recurrent and frequently alternate PFP is highlighted in this report, evidence for the benefit of oral steroids in acute PFP in MRS is provided, and the fact that PFP in MRS may have a rather benign course is reported.

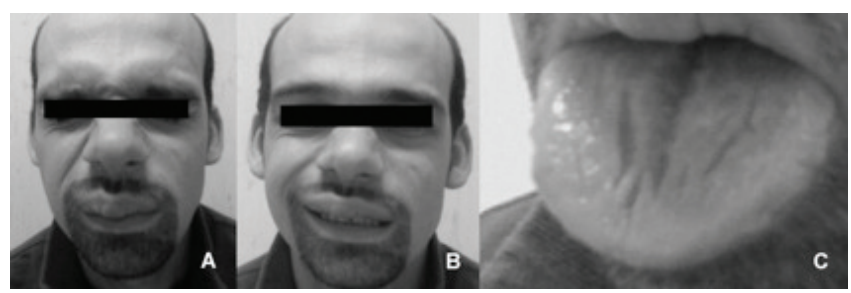

Figure. Left peripheral facial palsy and upper lip edema (A-B); lingua plicata with deep central fissure, radiating tongue fissures and irregular tongue edges (C).

Serviço de Neurologia, Hospital de Braga, Braga, Portugal.

Correspondence: João Pinho; Serviço de Neurologia, Hospital de Braga, Sete Fontes, São Victor; 4710-243 Braga - Portugal; E-mail: jdpinho@gmail.com

Conflict of interest: There is no conflict of interest to declare.

Received 10 July 2011; Received in final form 21 July 2011; Accepted 28 July 2011 


\section{References}

1. Ozgursoy OB, Ozgursoy SK, Tulunay O, Kemal O, Akyol A, Dursun G. Melkersson-Rosenthal syndrome revisited as a misdiagnosed disease. Am J Otolaryngol 2009;30:33-37.

2. Kaminagakura E, Jorge J. Melkersson-Rosenthal syndrome: a histopathological mistery and dermatologic challenge. J Cutan Pathol 2011;38:241-245.

3. Masson F, Barete S, Frémeaux-Bacchi V, et al. Melkersson-Rosenthal syndrome and acquired C1 inhibitor deficiency. Dermatology 2008;217:114-120.

4. Smeets E, Fryns JP, Berghe H. Melkersson-Rosenthal syndrome and de novo autosomal $t(9 ; 21)(p 11 ; p 11)$ translocation. Clin Genet 1994;45:323-324.

5. Kesler A, Vainstein G, Gadoth N. Melkersson-Rosenthal syndrome treated by methylprednisolone. Neurology 1998;51:1440-1441. 